\title{
Weaseling and the content of science
}

David Liggins

\begin{abstract}
I defend Joseph Melia's nominalist account of mathematics from an objection raised by Mark Colyvan.
\end{abstract}

The indispensability argument for the existence of mathematical entities such as numbers and sets has two premisses. The first is that mathematics is indispensable to science; that is, our best scientific theories imply the existence of numbers and other mathematical entities. The second premiss is a conditional: if mathematics is indispensable to science, then there are mathematical entities. These premisses entail that there are mathematical entities.

Let nominalism be the view that there are no mathematical entities. Nominalists offer different responses to the indispensability argument. One approach has been extensively discussed: that of Hartry Field (1980, 1989, 1991, 1992). Field rejects the first premiss of the indispensability argument: he claims that our best scientific theories can be re-written so as to avoid implying that there are numbers. To substantiate this claim, Field embarks on a formidable technical programme. The consensus is that it has not succeeded (see MacBride 1999 for an excellent survey); even Field (1998, p. 400) sounds rather sceptical about its prospects.

Recently, several philosophers have started to explore a different style of reply to the indispensability argument (see e.g. Melia 1995, 2000; Balaguer 1998, Chs 5 and 7; Yablo 2000, 2001; Azzouni 2004). This response consists of denying the second premiss of the indispensability argument. According to these nominalists, even if mathematics is indispensable to science, it does not follow that there are mathematical entities.

Three such philosophers are the target of Mark Colyvan's 'There is No Easy Road to Nominalism' (2010). In this paper, Colyvan argues that the views of Azzouni, Melia, and Yablo 
have no advantage over Fieldian nominalism: in particular, he argues that they run into more or less the same technical difficulties as Field's view. In this note, I argue that Colyvan's criticisms of Melia fail. For all Colyvan has said, Melia has suggested a form of nominalism which does not fall prey to the technical difficulties of Field's programme. I first set out Melia's view and Colyvan's criticism (Sect. 1); then I defend Melia from Colyvan (Sect. 2). In section 3 I rebut some possible objections.

1. Melia (2000, p. 467) considers utterances of the following form:

(1) Everyone who Fs also Gs. Except Harry-he's the one exception.

These utterances can be interpreted as self-contradictory:

(2) Everyone who $F$ s also $G$ s. And there is an $F$, Harry, who does not $G$.

But it is more charitable to interpret them as consistent:

(3) Everyone apart from Harry who Fs also Gs.

This is what Melia calls weaseling: conveying our view by taking back something implied by the sentence we have uttered.

When articulating their theories, scientists often say things which appear to imply the existence of mathematical entities. For instance, they quantify over numbers and functions. Melia (2000, p. 469) claims that 'almost all scientists ... deny that there are such things as mathematical objects'. It appears that these scientists are contradicting themselves. According to Melia, it is more charitable to regard them as weaseling: they convey their views by taking back something implied by the 
sentence they have uttered. They do so (he claims) because of the expressive limitations of language which does not imply the existence of mathematical objects (nominalistic language). The only possible way for the scientists to convey their views is to utter a sentence that implies the existence of numbers and then cancel the implication.

The significance of these claims for the indispensability argument is clear. If Melia is right, then although we write down our best scientific theories using mathematical language, and although these sentences imply the existence of mathematical objects, this gives us no reason to believe in mathematical objects. That there are mathematical objects is not part of the content of any of our best scientific theories; it is something said in order to help express this content. As Melia (1998, pp. 70-1) writes: '[M]athematics is used [in science] simply in order to make more things sayable about concrete objects'.

In response to Melia, Colyvan acknowledges that we sometimes engage in weaseling. In simple cases of weaseling, there is another way to articulate the content the speaker is trying to convey. For example, for each utterance of the form (1), the content the speaker intends to convey is given by the corresponding instance of (3). But, according to Colyvan, Melia does not offer another way of articulating the contents of our best scientific theories, and this means that he renders them obscure: 'if we cannot say what we want any other way except by weaseling, it's just not clear what we are saying' (Colyvan 2010, p. 295). Colyvan asserts that the only way of clarifying the contents of our best scientific theories is to provide a translation of them into nominalistic language. But to provide such a translation, he claims, is just to raise the same technical difficulties which plague Fieldian nominalism.

2. In this section, I will argue that (i) Colyvan's demand for a nominalistic restatement of all our best scientific theories is unreasonably strong; (ii) Melia has already met a more reasonable demand; (iii) consequently, his view does not render the contents of our best scientific theories obscure; and (iv) neither does it raise the technical difficulties comparable to Field's. 
To see why (i) is true, recall that it is part of Melia's position to claim that it is impossible to convey certain contents without weaseling. Presumably the sort of modality invoked here is practical impossibility; no stronger claim is required to explain why mathematics is actually used in science. So it is part of Melia's view that it is practically impossible to give a nominalistic translation of some of the claims made when expounding our best scientific theories. Colyvan's demand is therefore unreasonable: he is asking Melia to do something which by Melia's own lights is practically impossible. (It is rather like responding to the claim that some gases are invisible by demanding to see them all.)

Nevertheless, there is a more reasonable demand in the vicinity. It would be unsatisfactory for Melia to claim that scientists are aiming to convey certain contents but to refuse to say anything more about these contents except that they are nominalistic. Such a theory would indeed render these contents obscure. Colyvan is within his rights to ask Melia to tell us more about these contents. One way to meet this demand would be to give nominalistic restatements of some of them. I do not claim that it is the only way, but I will concentrate on it since Melia's writings already indicate how to do this. In the case of sentences ascribing physical quantities, Melia has in effect specified the content these sentences are intended to express. This goes some way to meeting Colyvan's unreasonable demand and goes all the way to meeting the more reasonable demand I have just laid out.

To begin with, let us focus on the case of distance. Consider Melia's discussion of the pimples on his nose (or, as he likes to call them, $a, b, c$, and $d$ ):

Maybe $a b$ is twice as long as $c d$. Maybe it is root two as long. Maybe it is $\pi$ times as long. How can we say these things without mentioning numbers? True, perhaps we could take some predicates such as ' $x y$ is-twice-as-long-as $z w$ ', and ' $x y$ is-root-two-as-long-as $z w$ ' as primitive four place predicates-not to be understood as expressing relations between $x, y, z, w$ and a number. ... But we will never find the time to learn [all the] infinitely many four place 
predicates ' $x y$ is- $r$-times-as-long-as $z w$ ' (cf. Davidson [1965]). So it may happen that, in order to specify the spatial relations that hold between $a, b, c$ and $d$, I have to refer to or quantify over numbers.... (Melia 1995, p. 228)

The idea here is that one five-place predicate can be used to index infinitely many four-place spatial relations. Suppose a scientist claims:

(4) The distance from A to B is 99.4 times the distance from C to D; but there is no such thing as the number 99.4 .

Then, in Melia's view, the claim that the scientist is trying to communicate is this, where 'is-99.4times-as-long-as' is a four-place predicate picking out a four-place spatial relation:

(4') $\mathrm{AB}$ is-99.4-times-as-long-as $\mathrm{CD}$.

Things are similar with the case of mass. In his review of Colyvan's book on the indispensability argument, Melia writes:

We can regard an explanation involving a chair's weighing eight kilograms as either appealing to a relation between the chair and the number eight, or as appealing to a property of the chair, a property that is (indispensably) referred to by using a number. On the second view, what is appealed to in the explanation is a nominalistic fact-the fact that the chair weighs what it does. But it may be that in order to appeal to this physical fact we have to quantify over numbers. (Melia 2003, p. 58)

I think the idea here is this. Consider the sentence: 
(5) The mass of the chair is $8 \mathrm{~kg}$.

Melia's view is that (5) entails the existence of the number 8: it claims that the chair bears the massin-kilograms relation to the number 8 . He denies that scientists believe in the number 8; presumably he thinks that they deny that (5) is true. The content that scientists are trying to convey when they utter (5) is this-where 'has-mass-8-kg' is a monadic predicate picking out a nominalistic mass property:

(5') The chair has-mass-8-kg.

In short, Melia's claim is that scientists' utterances of quantity-ascriptions are about the physical objects they seem to be about: they attribute nominalistic properties and relations to these entities. There need be no mystery about these properties: they are physical properties and their instantiation is subject to causal laws. The scales read ' $8 \mathrm{~kg}$ ' because the object on them has-mass-8-kg. (In their 2009, Daly and Langford expound and defend Melia's contention that the role of mathematics is to index, not explain.)

One might worry that this technique of translation works too well. If it delivered a translation of all the claims made when presenting our best scientific theories, it would undermine Melia's contention that this cannot be done. However, the technique does not deliver a translation of all scientific quantity-talk, as we can see by considering non-specific quantity-sentences. Measurement error means we are rarely in a position to make such claims like (5). We are more likely to say:

(6) The mass of the chair, in $\mathrm{kg}$, is between 7 and 9. 
In other words: for some number between 7 and 9, the chair bears the mass-in-kg relation to that number. Melia's 'indexing' strategy does not deliver a translation of such claims. Using Melia's favoured predicates, we might begin as follows:

(6?) The chair has-mass-7.000-kg, or the chair has-mass-7.001-kg, or the chair has-mass-7.002-kg, or $\ldots$

but it is clear that we will never be able to complete the sentence, since infinitely many disjuncts are needed (perhaps uncountably many). Although it is incomplete, (6?) still gives us some insight into what Melia thinks scientists claim when they utter (6). On Melia's view, they use (6) to ascribe one of certain nominalistic mass-properties to the chair.

This example makes it clear how quantification over numbers enhances our expressive power. Quantitative claims like (5) contain a place for a numeral; by quantifying into this place, we can express non-specific quantity-ascriptions like (6). Monadic mass-predicates lack this argument place, which is why they cannot be used to express such claims.

Melia has thus done a fair amount to explain what he sees as the subject matter of quantitative scientific claims; he does not render the contents of our best scientific theories obscure. It is wrong for Colyvan (2010, p. 295) to claim that 'we no longer have a grip on what is being said'. This establishes (ii) and (iii).

Finally, what of Colyvan's suggestion that Melia and Field are in the same boat, both committed to a taxing technical programme? I have two comments to make.

First, Melia and Field have different goals. Field aims to provide methods for nominalizing all of our best scientific theories. As I have argued, it is in Melia's interests to nominalize some parts of our best scientific theories; and he has already accomplished this. Melia does not nominalize all of our best scientific theories; indeed, we have seen that he cannot do so without contradicting himself. In addition, Field sets himself another demanding goal: he aims to show that reasoning using 
mathematics is conservative-roughly, that including mathematical premisses in an argument will only lead us to a nominalistic conclusion if that conclusion follows from the nominalistic premisses alone. Moreover, Field undertakes to provide a formal proof of this result. (For critical discussion, see MacBride 1999 and Melia 2006.) In contrast, Melia does not offer to prove or otherwise establish any conservativeness result. Since Melia's goals are less ambitious that Field's, we should expect Melia to have the easier time. In fact, it is not clear that Melia needs to pursue any technical programme at all.

Secondly, the resources used in Melia's treatment of quantities are much richer than those Field allows himself. To deal with distance, for instance, Field employs two predicates, 'Cong' and 'Bet'. Informally, ' $a b$ Cong $c d$ ' means 'length $a b$ is congruent to length $c d$ ', and ' $a$ Bet $b c$ ' means ' $a$ is between $b$ and $c^{\prime}$. For instance, Field translates

The distance from A to B is twice the distance from $\mathrm{C}$ to $\mathrm{D}$

as

There is a point $K$ such that: $K$ Bet $\mathrm{AB}$ and $\mathrm{A} K$ Cong $K \mathrm{~B}$ and $\mathrm{A} K$ Cong $\mathrm{CD}$.

In spite of his ingenuity, it is not clear that Field succeeds: for instance, it is hard to see how he can translate the claim:

The distance from A to B is $\pi$ times the distance from $\mathrm{C}$ to $\mathrm{D}$

(see Melia 1998, pp. 69-70). But it is trivial that Melia can translate this claim. All he has to do is to introduce a suitable four-place predicate: 
$\mathrm{AB}$ is- $\pi$-times-longer-than $\mathrm{CD}$.

The same goes for other quantities too, such as mass and temperature: Melia has more predicates at his disposal than Field, and this makes his task much easier.

In short, Melia is trying to do far less than Field, and has far richer resources to help him. So we should expect Melia's task to be significantly easier than Field's; whence (iv).

3. In this final section, I will consider two ways in which Colyvan might respond to these criticisms.

First of all, Colyvan might deny that there are the nominalistic quantity-properties and relations Melia posits. For example, Colyvan might claim that there is no such property has having-mass-8$\mathrm{kg}$ : to have mass $8 \mathrm{~kg}$ is to bear the mass-in-kg relation to the number 8 .

Such a position would be implausible, for familiar reasons (see e.g. Crane 1990). It seems arbitrary to privilege just one scale of measurement, such as the kilogram scale. And if we admit that there is also, say, the mass-in-lb relation, then we ought to explain why every object that bears mass-in-kg to 8 bears mass-in-lb to 17.6. The obvious explanation is that these objects instantiate an underlying property in virtue of which these relations obtain; but that would re-introduce Melia's nominalistic mass-properties. If Colyvan is to deny the existence of the nominalistic properties and relations invoked in Melia's theory, he ought to respond to these worries. (Here I echo Melia 1995, pp. 228-9.)

Second, Colyvan might claim that Melia ought to prove a conservativeness result. This response is initially attractive: after all, if mathematics were not conservative, then we might be led astray by using mathematical reasoning. Let us suppose, then, that Melia ought to claim that mathematics is conservative. It does not follow that he ought to offer a formal proof of this claim. Melia might instead offer an informal justification for the claim: he might supply many examples of conservative mathematical reasoning in science, and claim that there are no documented cases of nonconservative mathematical reasoning in science. Or Melia might avoid a specific argument for the 
conservativeness claim, and appeal to confirmational holism: he might say that the conservativeness claim is part of the account of applied mathematics with the best overall balance of benefits over costs. (Ad hominem point: as a confirmational holist—see chapter 2 of his 2001 -Colyvan should have no objection to this move.) So it is far from clear that Melia ought to prove any conservativeness result. (Nolan, Restall, and West 2005 pp. 322-3 offer moral fictionalists some ways to argue for conservativeness; these suggest options for Melia too.)

In summary: Colyvan's criticisms of Melia fail. I believe that similar considerations also dispatch Colyvan's criticisms of Yablo—but I lack the space to argue for that here. ${ }^{1}$

\section{References}

Azzouni, Jody 2004: Deflating Existential Consequence: A Case for Nominalism. New York: Oxford University Press.

Balaguer, Mark 1998: Platonism and Anti-Platonism in Mathematics. New York: Oxford University Press.

Bar-Hillel, Yehoshua (ed.) 1965: Logic, Methodology and Philosophy of Science: Proceedings of the 1964 International Congress. Amsterdam: North-Holland.

Boghossian, Paul and Christopher Peacocke (eds) 2000: New Essays on the A Priori. Oxford: Clarendon Press.

Colyvan, Mark 2001: The Indispensability of Mathematics. New York: Oxford University Press.

2010: 'There is No Easy Road to Nominalism'. Mind, 119, pp. 285-306.

Crane, Tim 1990: ‘An Alleged Analogy between Numbers and Propositions'. Analysis, 50, pp. $224-30$.

Daly, Chris and Simon Langford 2009: 'Mathematical Explanation and Indispensability Arguments'. Philosophical Quarterly, 59, pp. 641-58.

${ }^{1}$ Grateful thanks to Chris Daly for comments and discussion. 
Davidson, Donald 1965: 'Theories of Meaning and Learnable Languages'. In Bar-Hillel 1965, pp. 383-94.

Field, Hartry 1980: Science without Numbers: A Defence of Nominalism. Oxford: Blackwell.

1989: Realism, Mathematics and Modality. Oxford: Blackwell.

_1991: 'Metalogic and Modality'. Philosophical Studies, 62, pp. 1-22.

_1992: 'A Nominalistic Proof of the Conservativeness of Set Theory'. Journal of Philosophical Logic, 21, pp. 111-23.

_1998: 'Mathematical Objectivity and Mathematical Objects'. In Laurence and Macdonald 1998, pp. 387-403.

Laurence, Stephen and Cynthia Macdonald (eds) 1998: Contemporary Readings in the Foundations of Metaphysics. Oxford: Blackwell.

MacBride, Fraser 1999: 'Listening to Fictions: A Study of Fieldian Nominalism'. British Journal for the Philosophy of Science, 50, pp. 431-55.

Melia, Joseph 1995: 'On What There’s Not'. Analysis, 55, pp. 223-9.

—1998. 'Field's Programme: Some Interference'. Analysis, 58, pp. 63-71.

_2000: 'Weaseling Away the Indispensability Argument'. Mind, 109, pp. 455-79.

_2002: 'Response to Colyvan'. Mind, 111, pp. 75-80.

-2003. 'Defending the Indispensible'. Metascience, 12, pp. 55-8.

_2006. 'The Conservativeness of Mathematics'. Analysis, 66, pp. 202-8.

Nolan, Daniel, Greg Restall, and Caroline West 2005: 'Moral Fictionalism Versus The Rest'. Australasian Journal of Philosophy, 83, pp. 307-30.

Yablo, Stephen 2000: 'Apriority and Existence'. In Boghossian and Peacocke 2000, pp. 197-228.

2001: 'Go Figure: A Path through Fictionalism'. Midwest Studies in Philosophy, 25, pp. 72102. 